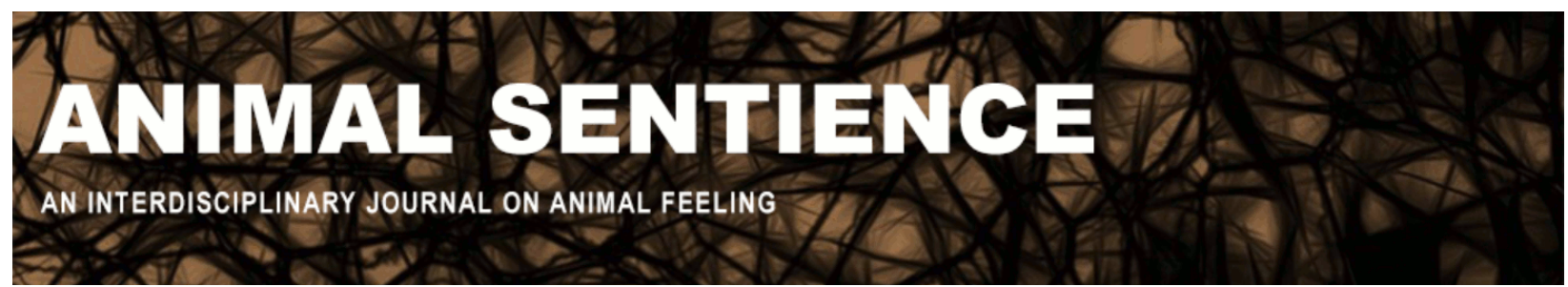

Merker, Bjorn (2016) Drawing the line on pain. Animal Sentience 3(23)

DOI: $10.51291 / 2377-7478.1062$

Date of submission: 2015-11-07

Date of acceptance: 2015-12-13

(c) (i)

This article has appeared in the journal Animal

Sentience, a peer-reviewed journal on animal

cognition and feeling. It has been made open access,

free for all, by WellBeing International and deposited

in the WBI Studies Repository. For more information,

please contact

wbisr-info@wellbeingintl.org.

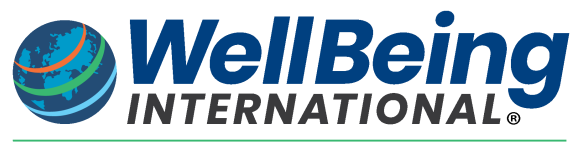

SOLUTIONS FOR PEOPLE, ANIMALS AND ENVIRONMENT 


\title{
Drawing the line on pain
}

Commentary on Key on Fish Pain

\author{
Bjorn Merker \\ Segeltorp, Sweden
}

\begin{abstract}
The structure of Key's (2016) argument that fish do not feel pain is flawed, betraying a fundamental lack of understanding of the nature of feelings and their role in the brain's functional division of labor. The evidence Key marshals in support of his premature commitment to an exclusively corticocentric view of consciousness in humans is plagued by repeated failures of scholarship.
\end{abstract}

\begin{abstract}
Bjorn Merker gyr694c@tninet.se is a neuroscientist with longstanding interest in brain mechanisms of consciousness: He has worked on subcortical mechanisms of orienting behavior in rodents and cats, mirror self-recognition in gibbons, and structural principles intrinsic to the neural organization of a conscious state. Fjälkestadsv. 410-82, SE-29194 Kristianstad, Sweden. http://loop.frontiersin.org/people/22911/bio
\end{abstract}

\section{The argument}

In his target article, "Why fish do not feel pain," Key (2016) reviews evidence that he takes to imply that fish, lacking a laminar, columnar pallium, cannot feel pain, because pain is a conscious modality, and consciousness is a function of such a pallium, and of it alone. The structure of his argument follows point by point the far more judiciously referenced and well presented argument by Rose that sparked the "fish pain controversy" more than a decade ago (Rose 2002), a source that goes unmentioned in Key's repeat performance.

The theoretical construct on which the twin arguments of Rose and Key turn is a distinction between conscious pain and unconscious nociception. Pain and the suffering it entails, being conscious experiences, are identified with the representation of activity in nociception-related circuitry of a laminar and columnar pallium on the assumption that such a structure alone is capable of generating experience of any kind. Having committed themselves to this assumption, it follows as a matter of course that any and all physiological or behavioral consequences of activity in nociception-related neural circuitry that occurs in the absence of such a structure must take place without consciousness.

Thus defined, the case for pain experience's being absent in all taxons that lack a laminar and columnar pallium is of course open-and-shut. No amount of evidence can contradict or falsify it because the category "nociception" will readily accommodate whatever may be observed 
neurally or behaviorally in the absence of such a structure, irrespective of its functional characteristics or level of sophistication. By this criterion not only are the "lowly" fishes excluded from even the first glimmer of conscious experience, but so are all amphibians and reptiles, and conspicuously also all birds. The latter are highly encephalized animals whose brain-body relations are distributed almost wholly in the mammalian range (van Dongen 1998, Fig. 23.3). Their telencephalic expansion has, however, occurred without the laminar specialization of the mammalian neocortex, and therefore excludes the very possibility of experience, according to the criteria in Key's list.

Further consequences follow from adopting that criterion. When a rat struggles against the insertion of a feeding tube, pushes at the tube with its forepaws, and squeals while so doing or, when given an injection, it utters high-pitched squeals "suggestive of pain," attempts to bite the syringe or the experimenter's hand, and licks the injection site - these behaviors are all deemed to unfold without a trace of experienced pain or discomfort when that rat lacks a neocortex because of surgical decerebration (as reported by Woods 1964, and interpreted by Rose 2012). In the same situation the behavior of intact rats is indistinguishable from that of the decerebrate ones (Woods 1964), yet now the pain-nociception distinction allows the presence of experienced pain and suffering because these animals possess the postulated "organ of consciousness," the neocortex (Rose 2012).

Notice that in this example the neocortex-based pain-nociception distinction forces us to conclude that the experience of discomfort and pain can be added to a perfectly unconscious physiological and behavioral process of fending off injurious stimulation without making a difference in observable behavior. On the face of it, there is of course no experience that is less likely to make no difference in overt behavior than that of pain and discomfort, for reasons we shall come to.

And if, nevertheless, we assume that it can be so added, and given that fish and decorticate rats are said to successfully escape and defend themselves from potentially injurious stimuli without experiencing pain and discomfort, then why can't we ourselves be spared the burden of those unpleasant feelings when fending off injury by similar behavioral means? If the sophisticated birds can do without them, as Key (who ties his stance to details of telencephalic organization specific to mammals) is committed to believing, then why not us? One begins to sense that a profound incomprehension of the nature and role of feelings in the brain's functional economy dwells at the origin of the pallial pain criterion.

These curious consequences follow directly from the assumption that a laminar and columnar pallium is the exclusive organ of consciousness, substituting - as a proxy - for actual evidence regarding experience in animals and humans lacking language. A detailed survey of evidence from neurosurgery and clinical studies, comparative neurology, experimental psychology, neurophysiology, and functional neuroanatomy concluded that this assumption regarding consciousness is not a safe one (Merker 2007). Neither Rose nor Key cite that paper, and though space does not allow me to recapitulate its contents here, principles developed in it bear directly on the fish-pain controversy. 
Mobile animals must meet their many simultaneously present and ever-changing bodily needs under diverse and constantly changing external circumstances. The latter prevent satisfaction of needs from being specified in purely motor terms, because the particulars of motor engagement must match unpredictable and changing external circumstances. Hence, there is the necessity for motivational systems designed to achieve invariant outcomes (goal states such as feeding) by imposing their biases on the operation of sensorimotor systems, one for each need (alimentation, water balance, reproduction, bodily integrity, etc.). Being many, these needs compete with one another for control over the musculoskeletal system, a limiting resource confined to executing essentially one act at a time (Lashley 1951; Morsella 2005; Merker 2007, 2013b).

For optimal outcomes, this competition for musculoskeletal access (time-sharing), and its necessary interaction with sensory circumstances, requires access to a "common currency" essentially shared coordinates in a unitary neural state-space - at a convergent bottleneck for behavioral control. (For formal details, see the pioneering analyses by Sibly and McFarland 1974, McFarland and Sibly 1975, and McFarland 1977. For how this bears on conscious function, see Section 4.2, in Merker 2007, and Merker 2013a.) Thus elevated to an interface with a sensory world, however primitive, these motivational signals become agents of the invariant outcomes of purposive behavior in the form of feelings of hunger, thirst, pain, et cetera.

Hedonic differences among feelings point us in the direction of different goal states by making us want to do different things. They also carry intrinsic information bearing on their priority or urgency of execution in the mutual competition of goal states for musculoskeletal control, and the inevitable trade-offs this entails. Thus pain feels "awful" and compelling because that is the way to ensure, on an innate basis, that it will take precedence over other bids for behavioral execution, a precedence commensurate with the importance of maintaining bodily integrity. This ability to displace other bids from musculoskeletal execution can accordingly be used to explore the issue of feelings in nonverbal animals, as has been done in experiments on pain in fish (references in Sneddon 2015).

The interface arrangement that allows motivational states to play this role is no less useful for a lowly fish than it is for a cerebral human. It is independent, in other words, of the degree to which the "sensory world" of a given taxon has been augmented with an elaborate system for veridically reconstructing the sources of sensory afference based on prior learning - the basic function of neocortex in mammals and of telencephalic elaboration in birds (Merker 2012). Thus, the courtship behavior of the smooth newt (Triturus vulgaris), which lacks a neocortex, served as empirical foil for one of McFarland's analytical treatments (McFarland 1977).

As we have seen, the decerebrate rat, whose highest brain compartment is the midbrain, fends off injury by matching defensive behavior appropriately to chances of injury that vary unpredictably. In other words, it is capable of purposive behavior, at least in response to the high-priority signal of pain. In terms of the above, this suggests that the decerebrate rat feels 
pain, ${ }^{1}$ because that feeling bias is needed to ensure the invariant outcome of attacking the source of the injurious disturbance. The neural equipment for doing so is not far to seek.

The vertebrate midbrain is crowned by the tectum/superior colliculus. Its sensory maps, representing all spatial senses including a body representation, are superimposed in exquisitely laminar fashion in premotor format. Its lavish connectivity includes reciprocal connections with the immediately underlying periaqueductal gray matter, representing basic motivational categories such as escapable and inescapable pain (Keay and Bandler 2002; Merker 2007, Fig. 4). Since the 40-year-old studies cited by Key, this midbrain structure has emerged as a high-level "priority gate" combining bottom-up "salience" with top-down "relevance" at the leading edge of purposive behavior (Boehnke and Munoz 2008; Fecteau and Munoz 2006; Lovejoy and Krauzlis 2010; Merker 2013b).

Thus, the tectal-periaqueductal complex may have the informational capacity and connectivity required of a candidate mechanism of elementary feeling states. To know whether fish do in fact feel pain, one must know what feelings are for, what consciousness is for, and what a laminar, columnar pallium is for - questions which neither Key nor Rose even broach. Once they are answered, it may well turn out that the line between pain and nociception should be drawn at the midbrain-hindbrain boundary rather than at the pallium-subpallium boundary, as Key would have it.

\section{The evidence}

Having found the structure of Key's argument wanting, I turn to the adequacy of the evidence he marshals, under two aspects. Do the studies he cites actually support the points for which he cites them? And, more generally, do those points in fact bear on the overall argument he would make with their help? To keep this commentary within bounds, I will concentrate on three clusters of evidentiary problems encumbering his treatment. They relate to gamma oscillations, the human lesion evidence, and information measures of putative "cortical consciousness."

Regarding the association of pain with cortical gamma oscillations, Key cites seventeen references in support of his assertion that local and long-range cortical synchrony and "binding" in the gamma range "have been consistently proposed to underlie pain and other feelings." A full twelve of these references do not even mention pain or feelings with one passing word. Only two of these twelve can be linked even indirectly to the topic in that they do mention consciousness. An additional reference (Ploner et al. 2009) does not even feature gamma

\footnotetext{
${ }^{1}$ Rose admits as much, saying that decerebrate rats "are even ostensibly purposive, a fact that makes behavioral distinction between nociception and pain very difficult" (Rose et al. 2012, p. 101), giving no reason for the qualification "ostensibly." Key does not even touch on such issues, moving in essentially binary fashion between unconscious spinal withdrawal reflexes and fully differentiated human-like "neocortical" pain, ignoring the elaborate intervening pain-related circuitry.
} 
oscillations. Therefore, counting generously, eleven and, strictly speaking, thirteen of the seventeen studies Key cites are irrelevant to his assertion.

Cortical gamma oscillations are, of course, associated with pain, as they are with every other dimension of information represented at the cortical level ever tested in this regard. The reason for this ubiquitous association is simple: cortical gamma oscillations are the infrastructural signature of functional cortical activation (details in Merker 2013c). The efficacy with which painful stimulation activates cortical tissue thus suffices to account for its association with gamma oscillations, analogously to its association with the far more sluggish BOLD signal (Merker 2013c). It is not for this reason, of course, that Key finds that association "exciting," but rather on account of the conjecture that gamma serves cortical "binding by synchrony" (Gray and Singer 1989; Singer and Gray 1995), and via it "consciousness" (Singer 1998). After twenty years of scrutiny of the "binding by synchrony" conjecture, a review of the wider topic of neuronal synchrony by a multi-author group that includes the principal proponent of the "binding by synchrony" conjecture concluded that that conjecture itself remains controversial (Uhlhaas et al., 2009). For a detailed analysis suggesting that it is not only controversial, but it is also in error on multiple counts, see Section 5 in Merker (2013c). A flawed attempt to link cortical gamma with cognition in general and with consciousness in particular cannot help Key establish a cortical locus of conscious pain.

Regarding Key's reading of the human lesion evidence, of the three cases of cerebral lesions reported by Biemond in 1956, only one was even claimed to have had complete loss of pain sensitivity in the affected body part (assessment method undisclosed), though not selectively so for pain: it was accompanied by a disturbance of all other somatic sensibility as well as paresis. One of the other cases experienced intractable pain in the affected body part so severe that the patient committed suicide.

Key presents the study of Cerrato et al. (2005) as follows: "Focal lesions to SI cause sensory loss of pain in discrete regions of the body and indicate that this cortical region is indeed necessary to feel pain." This study in fact reports only loss of pinprick pain and heat sensitivity in part of the right hand accompanied by hyperalgesia and a burning sensation in the same region. This hardly amounts to a loss of the capacity to experience pain. Similarly, the comprehensive review by Vierck et al. (2013) is concerned with the details of the primary somatosensory cortical representation of pain, and not with pain experience in general.

Detailed consideration of the many interesting studies reviewed by Vierck and colleagues is beyond the scope of this commentary. One of these allows me, however, to raise a cautionary point. At the higher levels of cutaneous laser stimulation, a patient with unilateral loss of somatosensory areas SI and SII "spontaneously described a 'clearly unpleasant' intensity dependent feeling emerging from an ill-localized and extended area 'somewhere between fingertips and shoulder', that he wanted to avoid" in the relevant body region (Ploner et al. 1999, p. 213). The aversive nature of this (clearly if poorly localized) "something," elicited by a painselective stimulus, places it in the domain of phenomenal pain, and may represent the pain analog of the phenomenal visual content that occurs in scotomas after primary visual cortex 
damage (Stoerig and Barth 2002). Such content was long thought not to occur, giving rise to the misnomer "blindsight." There is precedent, in other words, for phenomenal content surviving loss of a primary cortical sensory area.

Yet even if a cortical lesion or combination of lesions should eliminate the very capacity to experience pain in any form, which so far has not been demonstrated (Devor 2007), this by no means establishes the cortical origin of the information lost nor - should it originate cortically - that the neocortex is also the locus for its conscious perception. The information may belong to a subcortical site normally in receipt of neocortical projections for any number of functional reasons, a site rendered dysfunctional by its lesion-induced loss of normal cortical afference (von Monakov 1914; Carrera and Tononi 2014). This applies particularly to unilateral lesions, since these may "unbalance" subcortical systems, as shown by "curing" the deficit by a new lesion, this time subcortical, which restores the system's balance (Sprague 1966; Rushmore et al. 2006, and references therein).

Pending such controls, unilateral lesions - that is, almost all the lesion cases cited by Key - are to be accorded less weight than the rare cases of bilateral lesions, such as the case of complete bilateral loss of insula plus claustrum reported by Damasio et al. (2012). As pointed out by Devor et al. (2014), that patient's capacity to experience pain after loss of what on any account must be a major node of the neocortical pain system makes it difficult to argue, as Key does, that the paucity of experienced pain on cortical stimulation is occasioned by the failure of electrical stimulation to establish "the complex dynamics of neural activity in the cortex required for pain." Those dynamics are presumably disrupted by the loss of a major node like the Insula, yet pain is still experienced. Parenthetically, where (in a different context) Key cites the Devor et al. (2014) paper, he does so as if it supported the point Key is making, whereas in fact the conclusion of those authors was exactly what Key is arguing against. Key's treatment of the evidence for pain and consciousness in children with anencephaly or hydranencephaly also contains a number of errors easily corrected by reference to relevant papers that Key fails to cite (Merker 2007, 2008; Aleman and Merker 2014).

Moreover, even when those aspects of pain perception that are compromised by cortical lesions do in fact originate in the neocortex, they may not reach consciousness "in place" but in a subcortical locus of convergent descending neocortical projections. They issue from layer 5 pyramidal cells of every cortical area, without exception. In fact, such a situation may account for the importance of corticocortical feedback projections as a factor in conscious perception, cited by Key. Convergence of feedforward and feedback afference onto the dendritic trees of layer 5 pyramids, optimally disposed to integrate the two information streams (Larkum 2013), may be required for these cells to reach a sufficient activation state to pass the threshold of a recipient subcortical locus where that information then attains consciousness (Merker 2013b). In view of these multiple problems, the lesion evidence marshalled by Key fails to establish that a functional neocortex is either necessary or sufficient for the human experience of pain.

Finally, Key cites a set of theories and findings that attempt to support the conjecture that the cortex is the "organ of consciousness" based on evidence that various functional measures of 
cortical network connectivity exhibit co-variation with states of consciousness, from alertness over the stages of drowsiness and sleep, to anaesthesia, coma, and the vegetative state. This interpretation of the evidence confounds consciousness with cortical function. The various graph theory-based measures of operational network connectivity (e.g., the "phi" of Tononi and Koch 2015) measure cortical function whatever that function happens to be. The reason these measures correlate with conscious status is simply that the farther that status is from conscious alertness, the fewer actual operational tasks the cortex (along with a number of other parts of the brain) needs to perform. The correlations therefore tell us nothing about whether consciousness itself is one of those tasks. As already mentioned, the cortical information may well become conscious in a subcortical site of convergent cortical projections.

With that, the last major support for Key's insistence on a laminar, columnar pallium as the organ of consciousness fails to bear on his conjecture. Without securing that conjecture, his entire argument about the capacity of fish to experience pain, which rests squarely upon it, cannot even commence. I conclude that Key has not only produced a flawed argument, but he has also exhibited a failure of scholarship in attempting to support that argument with evidence.

\section{References}

Aleman, B. and Merker, B. (2014). Consciousness without cortex: a hydranencephaly family survey. Acta Paediatrica 103, 1057-1065.

Boehnke, S. E. and Munoz, D. P. (2008). On the importance of the transient visual response in the superior colliculus. Current Opinion in Neurobiology 18, 544-551.

Carrera, E. and Tononi, G. (2014). Diaschisis: past, present, future. Brain 137, 2408-2422.

Cerrato, P., Lentini, A., Baima, C., Grasso, M., Azzaro, C., Bosco, G., Bergamasco, B. and Benna, P. (2005). Pseudo-ulnar sensory loss in a patient from a small cortical infarct of the postcentral knob. Neurology 64, 1981-1982.

Damasio, A., Damasio, H. and Tranel, D. (2012). Persistence of feelings and sentience after bilateral damage of the insula. Cerebral Cortex 23, 833-846.

Devor, M. (2007). Pain, cortex, and consciousness. Behavioral and Brain Sciences 30, 89-90.

Devor, M., Rappaport, I. and Rappaport, H. (2014). Does the Golem feel pain? Moral instincts and ethical dilemmas concerning suffering and the brain. Pain Practice 15, 497-508.

Fecteau, J. H. and Munoz, D. P. (2006). Salience, relevance, and firing, a priority map for target selection. Trends in Cognitive Science 10, 382-390. 
Gray, C. M. and Singer, W. (1989). Stimulus-specific neuronal oscillations in orientation columns of cat visual cortex. Proceedings of the National Academy of Sciences USA 86, 1698-1702.

Keay, K. A. and Bandler, R. (2002). Distinct central representations of inescapable and escapable pain: Observations and speculation. Experimental Physiology 87, 275-279.

Key, B. (2016). Why fish do not feel pain. Animal Sentience 2016.003.

Kirschfeld, K. (1992). Oscillations in the insect brain: do they correspond to the cortical gammawaves of vertebrates? Proceedings of the National Academy of Sciences USA 89, 4764-4768.

Larkum, M. (2013). A cellular mechanism for cortical associations, an organizing principle for the cerebral cortex. Trends in Neuroscience 36, 141-151.

Lashley, K. S. (1951). The problem of serial order in behavior. In L. A. Jeffress (Ed.), Cerebral Mechanisms in Behavior (pp. 112-146). New York: Wiley.

Lovejoy, L. P. and Krauzlis, R. J. (2010). Inactivation of primate superior colliculus impairs covert selection of signals for perceptual judgments. Nature Neuroscience 13, 261-267.

Mazzola, L., Isnard, J., Peyron, R. and Mauguière, F. (2012). Stimulation of the human cortex and the experience of pain: Wilder Penfield's observations revisited. Brain 135, 631-640.

McFarland, D. J. and Sibly, R. M. (1975). The behavioural final common path. Philosophical Transactions of the Royal Society (London) B 270, 265-93.

McFarland, D. J. (1977). Decision making in animals. Nature 269, 15-21.

Merker, B. (2007). Consciousness without a cerebral cortex: A challenge for neuroscience and medicine. Target article with peer commentary and author response. Behavioral and Brain Sciences 30, 63-134.

Merker, B. (2008). Life expectancy in hydranencephaly. Clinical Neurology and Neurosurgery 110, 213-214.

Merker, B. (2012). From probabilities to percepts: A subcortical "global best estimate buffer" as locus of phenomenal experience. In S. Edelman, T. Fekete and N. Sachs (Eds.), Being in Time: Dynamical Models of Phenomenal Experience (pp. 37-79). Amsterdam: John Benjamins.

Merker, B. (2013a). Body and world as phenomenal contents of the brain's reality model. In A. Pereira, Jr. and D. Lehmann (Eds.), The Unity of Mind, Brain and World: Current Perspectives on a Science of Consciousness (pp. 7-42). Cambridge: Cambridge University Press. 
Merker, B. (2013b). The efference cascade, consciousness, and its self: Naturalizing the first person pivot of action control. Frontiers in Psychology 4, article 501, 1-20.

Merker, B. (2013c). Cortical gamma oscillations: the functional key is activation, not cognition. Neuroscience and Biobehavioral Reviews 37, 401-417.

Morsella, E. (2005) The function of phenomenal states: Supramodular interaction theory. Psychological Review 112, 1000-1021.

Ploner, M., Freund, H. J. and Schnitzler, A. (1999). Pain affect without pain sensation in a patient with a postcentral lesion. Pain 81, 211-214.

Rose, J. D. (2002). The neurobehavioral nature of fishes and the question of awareness and pain. Reviews in Fisheries Science 10, 1-38.

Rose, J. D., Arlinghaus, R., Cooke, S. J., Diggles, B. K., Sawynok, W., Stevens, E. D. and Wynne, C. D. L. (2012). Can fish really feel pain? Fish and Fisheries 15, 97-133.

Rushmore, R. J., Valero-Cabre, A., Lomber, S. G., Hilgetag, C. C. and Payne, B. R. (2006). Functional circuitry underlying visual neglect. Brain 29, 1803-1821.

Sibly, R. and McFarland, D. (1974). A state-space approach to motivation. In D. J. McFarland (Ed.), Motivational Control Systems Analysis (pp. 213-250). London: Academic Press.

Singer, W. and Gray, C. M. (1995). Visual feature integration and the temporal correlation hypothesis. Annual Review of Neuroscience 18, 555-586.

Sneddon, L. U. (2015). Pain in aquatic animals. The Journal of Experimental Biology 218, 967-976.

Sprague, J. M. (1966). Interaction of cortex and superior colliculus in mediation of visually guided behavior in the cat. Science 153, 1544-1547.

Stoerig, P. and Barth, E. (2001). Low-level phenomenal vision despite unilateral destruction of primary visual cortex. Consciousness and Cognition 10, 574-587.

Tononi, G. and Koch, C. (2015). Consciousness: here, there and everywhere? Philosophical Transactions of the Royal Society of London B: Biological Sciences, 370(1668), 20140167.

Van Dongen, P. A. M. (1998). Brain size in vertebrates. In R. Nieuwenhuys, H. J. ten Donkelaar and C. Nicholson (Eds.), The Central Nervous System of Vertebrates (Vol. 3, pp. 2099-2123). Berlin: Springer-Verlag.

Vierck, C. J., Whitsel, B. L., Favorov, O. V., Brown, A. W. and Tommerdahl, M. (2013). Role of primary somatosensory cortex in the coding of pain. Pain 154, 334-344. 
Von Monakow, C. (1914). Die Localization im Grosshirn und der Abbau der Funktion durch korticale Herde. Wiesbaden: JF Bergmann.

Woods, J. W. (1964). Behavior of chronic decerebrate rats. Journal of Neurophysiology 4, 635644. 